\title{
Australia's unprecedented future temperature extremes under Paris limits to warming
}

\author{
Sophie C. Lewis ${ }^{\mathrm{a}^{*}}$, Andrew D. King ${ }^{\mathrm{b}, \mathrm{c}}$ and Daniel M. Mitchell ${ }^{\mathrm{d}}$ \\ ${ }^{a}$ Fenner School of Environment and Society, The Australian National University, Canberra, \\ ACT, Australia \\ ${ }^{\mathrm{b}}$ School of Earth Sciences, The University of Melbourne, Parkville, Victoria, Australia \\ ${ }^{\mathrm{c}}$ ARC Centre of Excellence for Climate System Science \\ ${ }^{\mathrm{d}}$ School of Geographical Sciences, University of Bristol, Bristol, UK \\ Corresponding author: Tel: +61 26125 2623; email: sophie.lewis@anu.edu.au
}

\section{Abstract}

Record-breaking temperatures can detrimentally impact ecosystems, infrastructure, and human health. Previous studies show that climate change has influenced some observed extremes, which are expected to become more frequent under enhanced future warming. Understanding the magnitude, as a well as frequency, of such future extremes is critical for limiting detrimental impacts. We focus on temperature changes in Australian regions, including over a major coral reef-building area, and assess the potential magnitude of future extreme temperatures under Paris Agreement global warming targets $\left(1.5^{\circ} \mathrm{C}\right.$ and $\left.2^{\circ} \mathrm{C}\right)$. Under these limits to global mean warming, we determine a set of projected high-magnitude unprecedented Australian temperature extremes. These include extremes unexpected based on observational temperatures, including current record-breaking events. For example, while the difference in global-average warming during the hottest Australian summer and the $2^{\circ} \mathrm{C}$ Paris target is $1.1^{\circ} \mathrm{C}$, extremes of $2.4^{\circ} \mathrm{C}$ above the observed summer record are simulated. This example represents a more than doubling of the magnitude of extremes, compared with global mean change, and such temperatures are unexpected based on the observed record alone. Projected extremes do not necessarily scale linearly with mean global warming and this effect demonstrates the significant potential benefits of limiting warming to $1.5^{\circ} \mathrm{C}$, compared to $2^{\circ} \mathrm{C}$ or warmer.

\section{Key points}

- Assesses the possible magnitude of future extreme temperatures under 1.5 and $2^{\circ} \mathrm{C}$ of global warming

- Daily temperatures of $3.8^{\circ} \mathrm{C}$ above existing records simulated for Australian states

- Future extreme events do not necessarily scale linearly with global warming or previous records

This is the author manuscript accepted for publication and has undergone full peer review but has not been through the copyediting, typesetting, pagination and proofreading process, which may lead to differences between this version and the Version of Record. Please cite this article as doi: 10.1002/2017GL074612

This article is protected by copyright. All rights reserved. 


\section{Introduction}

Extreme weather and climate events are associated with significant risks to human and natural systems. This is demonstrated, for example, by the extreme high temperatures occurring during the 2003 European summer heatwave - most likely the hottest since at least 1500 AD [Stott et al., 2004] - and the 70,000 excess human heat deaths occurring during the event [Robine et al., 2008]. The characteristics of some high-impact extreme weather and climate events have already changed significantly over the instrumental period due to anthropogenic greenhouse gases [National Academies of Sciences, Engineering, Medicine, 2016]. This includes significant changes in the likelihood of the record European heatwave temperatures, which have been attributed to anthropogenic warming [Christidis et al., 2014], and the associated excess heat deaths which were also attributable to the climate change component of the heatwave [Mitchell et al., 2016]. Further changes in climatic extremes, and their associated impacts are expected with further warming, including under the $1.5^{\circ} \mathrm{C}$ and $2^{\circ} \mathrm{C}$ limits to global mean warming [King et al., 2017], which are keystone commitments of the Paris Agreement [UNFCCC, 2016].

Previous studies have explored the return times of current record-breaking events in future emissions scenarios [Christidis et al., 2014; Lewis et al., 2016] or under the Paris global mean warming targets [King et al., 2017].These approaches focus on the changing frequency of current extremes, which can usefully situate recent extremes in the context of anthropogenic climate change. For example, the record hot 2012/2013 Australian summer was found to be more likely due to anthropogenic greenhouse warming [Lewis and Karoly, 2013] and such an event is expected to occur more frequently under future warming [King et al., 2017]. Frequency- or likelihood-based approaches do not fully reveal the nature of extremes that adaptive planning approaches will need to consider as plausible future events. Further extreme event analysis has examined the future exceedance of a climatic metric above an arbitrary threshold [Pal and Eltahir, 2015]. However, these approaches also do not demonstrate the potential severity of future extremes.

We address this significant gap around how the magnitude of extreme temperatures events may differ from current conditions under the Paris Agreement warming limits. Understanding extremes expected under these thresholds is necessary for assessing the vulnerability of various systems to future climate change. While knowledge of the increased frequency of current record-breaking temperatures in the near future is valuable, adaptive decision-making requires knowledge of future record-breaking extremes that are unprecedented in the instrumental record (hereafter simply 'unprecedented').

Future record-breaking events are likely to exceed the adaptive learning implemented in the aftermath of current record events. This effect is readily demonstrated in social responses to increasingly extreme fire weather in Australia. Official recommendations about fire safety and preparedness from the 1983 Ash Wednesday fires successfully reduced the 
overall loss of life to fire [Bushfire Review Committee, 1984] only until the catastrophic fire weather of February 2009, which resulted in hundreds of deaths [Parker et al., 2014]. The 2009 conditions were unprecedented and unexpected, a 'black swan' event [Taleb, 2007] lying outside contemporary understandings of the range of climatic variability and systems resilience.

What high-impact, unprecedented events should adaptive planning consider as plausible in the future? Here, we present a framework for understanding changes in several highimpact, anthropogenically-influenced climate metrics for Australia under the Paris Agreement.

\section{Data and analysis}

We focus on investigating Australia's unprecedented future temperature extremes, as Australia is vulnerable to the impacts of anthropogenically-influenced heat extremes due to a combination of extreme high summer temperatures [Bureau of Meteorology, 2014], large populations residing in heatwave influenced climates such as in Melbourne and Sydney [Perkins, 2015] and a unique biogeography that includes the Great Barrier Reef (GBR).

We use a combination of observations and general circulation model (GCMs) datasets (summarized in Auxiliary Table 1) to assess how the magnitude of record-breaking events may change in the future. The HAPPI (Half a Degree Additional warming, Prognosis and Projected Impacts) [Mitchell et al., 2017] is specifically designed for examining how extreme events might differ in worlds that are $1.5^{\circ} \mathrm{C}$ and $2^{\circ} \mathrm{C}$ warmer than pre-industrial, and have not yet been applied to Australia. GCMs from the fifth phase of the Coupled Model Intercomparison Project (CMIP5) [Taylor et al., 2012] are used in conjunction with HAPPI to inform different aspects of the analysis, which are detailed further below.

\subsection{Observations and climate metrics}

Observations of Australian land surface temperatures are derived from the Australian Water Availability Project (AWAP) gridded data product [Jones et al., 2009], beginning in 1910. For Coral Sea regional temperatures, seasonal values are determined from HadCRUT4 [Morice et al., 2012] using years 1910-2016, as data prior to this time were spatially inconsistent. The climatic metrics analyzed are:

1. Aus DJF Tmean: Australia area-mean (50-10 $\left.\mathrm{S}, 110-155^{\circ} \mathrm{E}\right)$ summer (December-February, DJF) temperatures. The record-breaking summer temperature anomaly of 2012/2013 [Bureau of Meteorology, 2014] was significantly influenced by anthropogenic warming [Lewis and Karoly, 2013] and associated with substantial socio-economic impacts, including bushfires in southeastern Australia. 
2. Coral Sea MAM Tmean: Mean temperature in the Coral Sea $\left(26^{\circ} S-4^{\circ} S, 142^{\circ} E-\right.$ $174^{\circ} \mathrm{E}$; region shown in Fig. 1a) for the austral autumn (March to May; MAM). In 2016, record high sea surface temperatures (SSTs) occurred in the Coral Sea region in MAM [Bureau of Meteorology, 2016] coincident with extreme bleaching of the Great Barrier Reef [Cressey, 2016], which is associated with heat stress [Normille, 2016; Hughes et al., 2017b]. The United Nations World Heritage listed GBR site is of significant scientific, social, political and economic interest. Coral Sea surface air temperatures, which are highly correlated with SSTs, are explored.

3. VIC daily Jan Tmax/ NSW daily Jan Tmax: Daily maximum January temperatures for Victoria State-wide and New South Wales/Australian Capital Territory (NSW/ACT) area-averages (region shown in Fig. 1a). In January 2013, Australia as a whole experienced its hottest day in the instrumental record, measuring $40.30^{\circ} \mathrm{C}$ [Bureau of Meteorology, 2013]. A total of 44 stations set alltime daily maximum temperature records in 2012/2013, including in Sydney and Canberra, with the equivalent record set for Melbourne in 2014 [Trewin, 2014]. The combined population of these urban centers exceeds 9.8 million people who are at potential risk of adverse health outcomes due to excess heat stress [Victorian Department of Health, 2009]. The all-time January daily Tmax records were set during the Black Friday bushfires in 1939, with the highest subsequent value set in Victoria in 2009. During the 2009 heatwave event in Victoria, the highest ever all-time daily Tmax value occurred, although this event transpired in February.

\subsection{HAPPI data}

Future changes in metrics are first explored in the HAPPI framework which simulates current climate, and both $1.5^{\circ} \mathrm{C}$ and $2^{\circ} \mathrm{C}$ of global mean warming. These limits to warming are key aspirations of the Paris Agreement of 2015, which commits to 'Holding the increase in the global average temperature to well below $2^{\circ} \mathrm{C}$ above pre-industrial levels and to pursue efforts to limit the temperature increase to $1.5^{\circ} \mathrm{C}$ above pre-industrial levels, recognizing that this would significantly reduce the risks and impacts of climate change' [UNFCCC, 2016]. Participating models (at the time of writing: NorESM1, MIROC5 ${ }^{1}$, CanAM4 and Cam4-degree) contribute large atmosphere-only ensembles for three decade-length timeslices, including 2006-2015 (-HAPPI $2006-2015)$ and $2106-2115$ under $1.5^{\circ} \mathrm{C}$ and $2^{\circ} \mathrm{C}$ $\left(\mathrm{HAPPI}{ }_{1.5}\right.$ and $\mathrm{HAPPI}_{2}$ ) of warming. We use 895 realizations of monthly Tmean data and 460 realizations of daily Tmax data. Regional area-mean temperatures are calculated for all climate metrics in each HAPPI realization.

\footnotetext{
${ }^{1}$ At the time of writing the MIROC $1.5^{\circ} \mathrm{C}$ SSTs were prescribed marginally too hot in the global average (by $\left.0.15^{\circ} \mathrm{C}\right)$.
} 
The HAPPI data are first compared to observations (described in Auxiliary material) to evaluate how well observed variability is simulated and how well the multi-model ensemble mean matches observed. For daily values, where a very large model dataset is available for analysis, the variability of simulated HAPPI values lies within the observed range, with simulations for NSW lying at the lower end of observed variability. For Australian DJF Tmean, the simulated variability is notably higher than observed, indicating that a greater range of possible temperatures is simulated for a given SST state compared to observed. The mean observed conditions of the recent decade (2006-2015) are higher than the HAPPI ensemble mean for summer Australia-wide temperatures (Fig. 1b), although the mean observed values are comparable to the HAPPI ensemble mean for Coral Sea MAM Tmean (Fig. 1c) and VIC and NSW daily Jan Tmax (Fig. 1d and e). Nonetheless, the observed decadal mean value for 2006-2015 lies within the $\mathrm{HAPPI}_{2006-2015}$ range.

Biases in HAPPI may result in either under- or over-estimating the severity of future extremes or their timing. These differences in modeled and observed summer temperatures may transpire from several sources. As the HAPPI $\mathrm{H}_{2006-2015}$ simulations are forced by observed SSTs, which samples the range of different SST conditions of this decade [Mitchell et al., 2017], the higher observed temperatures suggest these integrate critical non-SST related climatic factors or atmospheric composition related climatic factors, such as land-air coupling strength or atmospheric flow dynamics. A cold bias is not prohibitive to exploring upper tail extremes in the HAPPI framework, as such a bias would impact both $1.5^{\circ} \mathrm{C}$ and $2^{\circ} \mathrm{C}$ scenarios similarly and hence permit comparison, and mean cold biases would make future extreme summer estimates conservative, although this effect may be offset by the simulated increased variability compared to observed. As such, estimates of future extremes provided in this study are constrained using observed records and used in conjunction with CMIP5 data, which are detailed below.

\subsubsection{Defining unprecedented extremes}

We use two analytical steps to assess possible future extreme events that are unprecedented within the observational record. First, we apply an observational constraint to simulated extreme $\mathrm{HAPPI}_{1.5}$ and $\mathrm{HAPPI}_{2}$ values using the current observed record and variability. That is, we calculate the equivalent range in the HAPPI models that corresponds to the range (extending from observed average to observed record) in the observational distributions. The number of observed standard deviations above the 2006-2015 mean $\left(N \sigma_{\text {obsmax }}\right)$ that defines the observed maximum value $\left(\mathrm{Obs}_{\mathrm{Max}}\right)$ is first determined. We then determine the equivalent range of extreme values in $\mathrm{HAPPI}_{1.5}$ and $\mathrm{HAPPI}_{2}$, based on the ensemble standard deviation $\left(\sigma_{\text {HAPPI1.5; }} ; \sigma_{\text {HAPPI2 }}\right)$ in the $1.5^{\circ} \mathrm{C}$ and $2^{\circ} \mathrm{C}$ degree futures and the observed anomaly:

$\mathrm{HAPPI}_{1.5 / \text { Obs }}=\left(\right.$ Ensemble mean $\left.\left._{\text {HAPPI1.5 }}\right)+\left(\mathrm{N \sigma}_{\text {Obs_max }_{\text {max }}}{ }^{*} \sigma_{\text {HAPPI1.5 }}\right) \quad 1 \mathrm{a}\right)$ $\mathrm{HAPPI}_{2 / \mathrm{Obs}}=\left(\right.$ Ensemble mean $\left.\left._{\mathrm{HAPPI} 2}\right)+\left(\mathrm{N} \sigma_{\text {Obs_max }_{\text {max }}}{ }^{*} \sigma_{\mathrm{HAPPI} 122}\right) 1 \mathrm{~b}\right)$ 
Second, we determine the $99^{\text {th }}$ percentile ensemble value $\left(\mathrm{HAPPI}_{1.5 / 99} ; \mathrm{HAPPI}_{2 / 99}\right)$ and compare this value to the observed record anomaly. While record-breaking extremes are of primary interest in the instrumental period, we apply a conservative approach here and do not focus on the most anomalous (record-breaking) values in HAPPI. For comparison, we also calculate the value of two simulated standard deviations $\left(2^{*} \sigma_{\text {HAPPI }}\right)$ above the HAPPI ensemble mean $\left(\mathrm{HAPPI}_{1.5 / 2 \sigma} ; \mathrm{HAPPI}_{2 / 2 \sigma}\right)$.

We define two categories of unprecedented events based on this analysis. Plausible events are expected in HAPPI if a warming threshold is breached ('plausible events'). These are simulated future events of magnitude up to the observationally constrained value in HAPPI (Ensemble mean ${ }_{\text {HAPPI }}+\mathrm{N \sigma}_{\max }{ }^{*} \sigma_{\text {HAPPI }}$ ), where this constrained value is lower than $\mathrm{HAPPI}_{99}$. This means that an event of this severity must occur within the ensemble $99^{\text {th }}$ percentile range; where extremes up to $\mathrm{HAPPI}_{\text {obs }}$ values occur within the $\mathrm{HAPPI}_{99}$ range, events of these magnitudes are considered plausible under this prescribed level of global mean warming. Second, we define 'black swan events' as simulated events in HAPPI that would not be anticipated simply based on the characteristics of record-breaking during the instrumental period. Where events of greater magnitude than expected by the observational constraint are simulated in $\mathrm{HAPPI}_{99}$, these are described as black swans. In summary, black swan events are the simulated $\mathrm{HAPPI}_{99}$ values in each scenario that are greater in magnitude than both the current record and the observationally constrained value.

\subsection{CMIP5 data and analysis}

We use CMIP5 model data to complement HAPPI results in two ways. First, CMIP5 models are used to situate in time the extreme values determined from HAPPI. We investigate the time when the $1.5^{\circ} \mathrm{C}$ and $2^{\circ} \mathrm{C}$ thresholds are breached for Australian annual average temperatures in the current emissions trajectory (RCP8.5) [Peters et al., 2012] and an aggressive mitigation scenario (RCP2.6). We define the time of exceedance (ToE) of these thresholds as having occurred when in any subsequent 10 -year period, $50 \%$ of anomalies exceed this threshold in the majority of model realizations. We note that the $1.5^{\circ} \mathrm{C}$ and $2^{\circ} \mathrm{C}$ thresholds refer to global average temperatures, although the ToE determined here is consistent with global estimates [Henley and King, 2017]. Second, CMIP5 models are used as a constraint on the potential severity of Australian temperature extremes in the 21stCentury. End of the 21st-Century temperature extremes are calculated from RCP2.6 and RCP8.5 experiments. The $95^{\text {th }}$ percentile value RCP8.5 value across the multi-model ensemble of maximum values during $2091-2100$ is calculated. This analysis provides a useful extension to HAPPI, which imposes $1.5^{\circ} \mathrm{C}$ and $2^{\circ} \mathrm{C}$ warming limits.

We used simulated monthly (tas) and daily (tasmax) data for historical, RCP2.6 and RCP8.5 experiments [Taylor et al., 2012] from a suite of models. A distinct ensemble of CMIP5 models was used for investigating each climate metric based on their skill in simulating observed climatic variability (see Auxiliary material). Regional area-mean 
temperatures are calculated for Australia for DJF for land surface gridboxes, for the Coral Sea region for MAM for ocean gridboxes and daily Jan Tmax temperatures are calculated for Victoria and NSW State-wide area-averages. Area-average temperature anomalies are calculated relative to each model's 1850-1900 climatology, which here defines pre-industrial.

\section{Results}

The magnitude of future extremes under Paris Agreement limits to warming is first examined in HAPPI. The HAPPI multi-model ensemble mean of maximum simulated values are substantially higher than maximum observed values for the $1.5^{\circ} \mathrm{C}$ and $2{ }^{\circ} \mathrm{C}$ experiments for Aus DJF Tmean and Coral Sea MAM Tmean (Fig. 1, HAPPI panels b and c). The ensemble mean maximum Australian DJF values are $0.42-0.80^{\circ} \mathrm{C}$ above the observed record for the $1.5^{\circ} \mathrm{C}$ and $2^{\circ} \mathrm{C}$ HAPPI scenarios respectively. The simulated ensemble mean of maximum HAPPI daily Tmax values is lower than the observed for NSW, although VIC Tmax values $1.5-1.95^{\circ} \mathrm{C}$ above observed are simulated in HAPPI warming scenarios (Fig. 2). Notably, the simulated multi-model ensemble mean maximum values under $1.5^{\circ} \mathrm{C}$ and $2^{\circ} \mathrm{C}$ scenarios do not necessarily reflect simple additive warming in which half a degree of additional warming corresponds to extremes half a degree more severe, which is next explored.

The potential magnitude of extreme temperatures under the $1.5^{\circ} \mathrm{C}$ and $2^{\circ} \mathrm{C}$ warming thresholds within this large ensemble of realizations is investigated (shown Fig. 2 , summarized in Table 1). Under $1.5^{\circ} \mathrm{C}$ of warming above a pre-industrial baseline, simulated $\mathrm{HAPPI}_{99}$ events include Australian DJF Tmean values of $30.1^{\circ} \mathrm{C}$ and $30.5^{\circ} \mathrm{C}$ in response to $2^{\circ} \mathrm{C}$ of global mean warming $\left(\mathrm{HAPPI}_{2 / 99}\right)$. The magnitude of these Australian DJF Tmean events is next constrained by the magnitude of observed record-breaking events $\left(\mathrm{HAPPI}_{1.5 / \mathrm{Obs}} ; \mathrm{HAPPI}_{2 / \mathrm{Obs}}\right)$, showing that these simulated values are as anomalous again as the record 2012/012 event observed in the last decade. As the calculated observationally constrained range value ( $\mathrm{HAPPI}_{\mathrm{Obs}}$ ) in each scenario is lower than $\mathrm{HAPPI}_{99}$ value, extremes of such a magnitude are categorized as plausible if this warming threshold is breached. Australian DJF temperatures $0.2^{\circ} \mathrm{C}$ and $0.4^{\circ} \mathrm{C}$ above the $2012 / 2013$ record (Table 1 ), are thus categorized as plausible events under $1.5^{\circ} \mathrm{C}$ and $2^{\circ} \mathrm{C}$ of warming respectively.

Where the $\mathrm{HAPPI}_{99}$ value is above both any observed value $\left(\mathrm{Obs}_{\max }\right)$ and the observationally constrained projected estimate ( $\left.\mathrm{HAPPI}_{2 / \mathrm{Obs}}\right)$, anomalies up to this magnitude are categorized as black swan events. Under $2^{\circ} \mathrm{C}$ of warming, summer extremes of $2.4^{\circ} \mathrm{C}$ above observed in 2012/2013 are simulated. These black swan future Australian summer temperature events do not scale linearly to mean global warming, nor are necessarily indicated by the magnitude of currently observed extreme anomalies. For example, while the difference in global-average warming during the hottest Australian summer and the $2^{\circ} \mathrm{C}$ Paris target is $1.1^{\circ} \mathrm{C}$, extremes of $2.4^{\circ} \mathrm{C}$ above the summer record are simulated. For extreme Coral Sea MAM temperatures, events of $0.8^{\circ} \mathrm{C}$ above the 2016 record are 
simulated in $\mathrm{HAPPI}_{1.5}$. The observationally constrained value indicates warming events of $27.7^{\circ} \mathrm{C}$ and $28.6^{\circ} \mathrm{C}$ are plausible in the $1.5^{\circ} \mathrm{C}$ and $2^{\circ} \mathrm{C}$ HAPPI experiments.

Observed daily temperatures are more variable than seasonal values and the existing records (Table 1) are up to three standard deviations above mean. The HAPPI ${ }_{1.5} 99^{\text {th }}$ percentile values for VIC daily Jan Tmax values of $40.4^{\circ} \mathrm{C}$ and NSW daily Jan Tmax of $40.5^{\circ} \mathrm{C}$ are simulated. These values fall below the value of current observed records (Fig $2 \mathrm{C}$ and d). However, in $\mathrm{HAPPI}_{2}$, simulated January daily extreme values exceed those observed, with $47.9^{\circ} \mathrm{C}$ daily Jan Tmax values occurring in NSW and $46.8^{\circ} \mathrm{C}$ occurring in Victoria. These State-average percentile values simulated under $2^{\circ} \mathrm{C}$ of global warming are above the expected values based on the observational constraint $\left(N \sigma_{\text {Obsmax }}\right)$. That is, events of up to $44.9^{\circ} \mathrm{C}$ in VIC and $47.2^{\circ} \mathrm{C}$ in NSW are plausible based on observed statistics, but events of magnitude well above these plausible values are simulated under $2^{\circ} \mathrm{C}$ of global mean warming.

Next, CMIP5 models are used in conjunction with HAPPI results to situate these simulated extreme events in time. Frist, the dates when Australian annual average temperatures breach the $1.5^{\circ} \mathrm{C}$ and $2^{\circ} \mathrm{C}$ Paris thresholds are calculated for RCP8.5 and RCP2.6 experiments. The time of exceedance of warming is similar for RCP8.5 and RCP2.6 scenarios for $1.5^{\circ} \mathrm{C}$ of warming above pre-industrial and occurs in the 2030s (indicated in Fig. 3a). For the $2^{\circ} \mathrm{C}$ limit to warming, the median time such values are exceeded occurs in the 2040s for RCP8.5 and 2060s for RCP2.6 (solid arrows in Fig. 3a). Using the CMIP5 multi-model median warming in these scenarios to situate the $\mathrm{HAPPI}_{1.5}$ and $\mathrm{HAPPI}_{2}$ plausible and black swan climatic events (shown Table 1) in time indicates these occur by 2060-2070 at the latest (RCP2.6).

In addition, CMIP5 models demonstrate the possible magnitude of future extreme temperatures over the $21^{\text {st }}$ Century under projected global mean warming greater than $2^{\circ} \mathrm{C}$. Higher magnitude events again (above HAPPI) are simulated at the end of the century in the RCP8.5 scenario (solid horizontal bars in Fig. 3). Extreme value ( $95^{\text {th }}$ percentile) anomalies of $4.1^{\circ} \mathrm{C}$ above the $2^{\circ} \mathrm{C} \mathrm{HAPPI}$ g9 values for Australia DJF Tmean occur in $2090-2100,3.1^{\circ} \mathrm{C}$ for Coral Sea MAM Tmean and $3.6^{\circ} \mathrm{C}$ for daily January Tmax. End of 21st-Century CMIP5 anomalies show that while extremes $\mathrm{HAPPI}_{1.5}$ and $\mathrm{HAPPI}_{2}$ are higher for all metrics than those observed in the instrumental record, these do not represent the full magnitude of possible future extreme events. Rather $\mathrm{HAPPI}_{1.5}$ and $\mathrm{HAPPI}_{2}$ extreme values demonstrate plausible future extremes under substantially limited warming than possible throughout the 21st-Century.

\section{Discussion and conclusions}

Recent studies demonstrate the value of limiting global mean warming for avoiding exposure to extremes [Lewis et al., 2016; Ciavarella et al., 2017; King et al., 2017]. Such 
studies typically focus on the increased frequency of current records under various scenarios, or the time of emergence of unfamiliar climates [Frame et al., 2017]. Our present results additionally demonstrate the value of limiting mean global warming for preventing temperatures extremes of a magnitude unprecedented in the instrumental record.

Under the ambitious Paris Agreement target of limiting warming to $1.5^{\circ} \mathrm{C}$ above preindustrial levels, extreme Australian summer temperatures $0.2-2.0^{\circ} \mathrm{C}$ above the $2012 / 2013$ record are simulated (from Table 1). Under $2^{\circ} \mathrm{C}$ of mean warming, plausible summer extremes of $0.6-2.4^{\circ} \mathrm{C}$ above the $2012 / 2012$ event are simulated. For Coral Sea region autumn temperatures, extremes of $0.3-0.8^{\circ} \mathrm{C}$ above the 2016 record occur under the $1.5^{\circ} \mathrm{C}$ Paris target, and $0.6-1.2^{\circ} \mathrm{C}$ under the $2^{\circ} \mathrm{C}$ target. Using CMIP5 simulations, we find that under a continued high emissions scenario, these high magnitude extremes may occur by $2030-2040$ for $1.5^{\circ} \mathrm{C}$ of mean warming and by $2040-2050$ for $2^{\circ} \mathrm{C}$ of mean warming. The timing of exceedance of Australian mean warming calculated here supports global calculation estimates [Henley and King, 2017], and demonstrates that under the current emissions trajectory, increasingly severe extremes are likely by the end of the 21st-Century.

These simulated extreme events do not necessarily scale linearly with global mean warming or necessarily with previous record anomalies. For Australian summer temperatures, anomalies are simulated in HAPPI that exceed the degree of anomaly of the maximum observed value, relative to variability. Hence, although difference in globally average warming during the hottest summer in Australian history (the so-called Angry Summer of $2012 / 2013$ ) and the $2^{\circ} \mathrm{C}$ Paris Agreement target is $1.1^{\circ} \mathrm{C}$, the HAPPI simulated extremes of $2.4^{\circ} \mathrm{C}$ above the existing observed record, represents a more than doubling of the magnitude of extreme- compared with mean-climate change.

For the Coral Sea region metric, where near-surface temperatures are tightly coupled to SSTs and variability is subdued, the HAPPI simulated temperature extremes scale closely to mean warming. The framework presented here may be more suitable for understanding land-based, rather than ocean-based, extremes for various reasons. First, thresholds of $1.5^{\circ} \mathrm{C}$ and $2^{\circ} \mathrm{C}$ warming above pre-industrial refer to near-surface, rather than surface temperatures, which are likely to be substantially lower for oceans [Hughes et al., 2017a]. Furthermore, the atmosphere-only SST-forced timeslice framework of HAPPI limits the approach presented here for quantitatively understanding future temperature extremes in the Coral Sea region.

For each metric, we have categorized events that both scale with maximum observed records and are simulated in each HAPPI scenario as plausible. Based on these HAPPI simulations and the characteristics of the instrumental record, these events are considered plausible if the Paris-stipulated limits to global mean warming are exceeded. In addition, we categorize events simulated in HAPPI above the scale observed record constraint $\left(\mathrm{N \sigma}_{\text {obsmax }}\right)$ as 'black swan' events, as the instrumental record may provide limited insight into 
improbable but high-impact extremes of these metrics. For record daily maximum January temperatures in Victoria, temperatures $2.3^{\circ} \mathrm{C}$ above the existing record occur in $\mathrm{HAPPI}_{2}$ experiments, and $3.8^{\circ} \mathrm{C}$ for NSW. The existing highest daily Tmax value for Victoria occurred on February 2009 , where State-wide temperatures of $44.5^{\circ} \mathrm{C}$ and Melbourne city temperatures of $46.4^{\circ} \mathrm{C}$ occurred in association with catastrophic bushfires and heatwaves.

The severity of possible future temperature extremes poses serious challenges for preparedness for future climatic change. The enhanced Victoria and NSW extremes simulated in HAPPI indicate the possibility that sites within major Australian cities, such Sydney or Melbourne, could incur unprecedented temperatures of $50^{\circ} \mathrm{C}$ under $2^{\circ} \mathrm{C}$ of global mean warming. While insights into the timing of such extremes likely depends on the validity of the models used here, such unprecedented temperatures would present onerous challenges to human and natural systems [Perkins, 2015]. The magnitude of such extremes is decreased by curbing warming at $1.5^{\circ} \mathrm{C}$, but increased by maintaining emissions at the RCP8.5 trajectory. For the Coral Sea region, the present results of increasing high magnitude future extremes support recent studies that demonstrate significant challenges are posed for the resilience of natural systems, such as the Great Barrier Reef, under $1.5^{\circ} \mathrm{C}$ or $2^{\circ} \mathrm{C}$ of warming [Hughes et al., 2017b].

This study provides broad guidance about the magnitude of plausible extreme events in various future warming scenarios, with a focus on Australia. The precise values of extremes simulated in either the HAPPI or CMIP5 model dataset should not, however, be interpreted prescriptively. The model-dependence or SST-sensitivity of the magnitude of future extremes has not yet been examined. While a large model dataset and a variety of model configurations are used, the comparison of $\mathrm{HAPPI}_{2006-2015}$ with observations demonstrates differing skill in capturing the observed temperature means and variability for each metric. For example, the Australian summer Tmean mean value is lower than observed, but the variability is greater, which may impact the precise occurrence in the timing and/or severity of the extremes simulated. The simulation of daily Tmax extremes in HAPPI is, however, more comparable to observed. As such, the framework developed here for assessing the possible magnitude of extremes should be broadly applied to various events and regions in order to provide expanded information about a range of possible future extreme events.

\section{Acknowledgements}

We acknowledge the support of the $\mathrm{NCl}$ facility in Australia and we acknowledge the World Climate Research Programme's Working Group on Coupled Modelling, which is responsible for CMIP, and we thank the climate modeling groups for producing and making available their model output. We thank the Bureau of Meteorology, the Bureau of Rural Sciences and CSIRO for providing the Australian Water Availability Project (AWAP) data. The data used are listed in references and available for public download. S.C.L is funded through the Australian Research Council Centre (DE160100092). A.D.K. is funded through 
the Australian Research Council Centre of Excellence for Climate System Science (CE110001028). D.M.M is funded by a NERC independent research fellowship (NE/N014057/1).

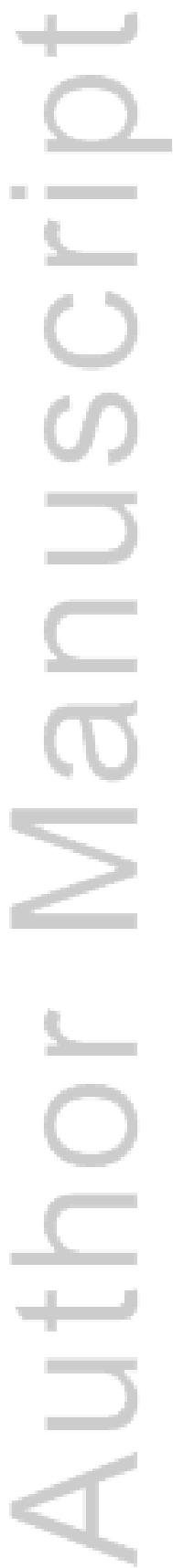

This article is protected by copyright. All rights reserved. 


\section{References}

Bureau of Meteorology (2013), Extreme heat in January 2013. Special Climate Statement 43.

Bureau of Meteorology (2014), Annual Climate Report 2013.

Bureau of Meteorology (2016), Special Climate Statement 56-Australia's warmest autumn on record.

Bushfire Review Committee (1984), Report of the Bushfire Review Committee: On Bush Fire Disaster Preparedness and Response in Victoria, Australia, Following the Ash Wednesday Fires, Melbourne : Government Printer.

Christidis, N., G. S. Jones, and P. A. Stott (2014), Dramatically increasing chance of extremely hot summers since the 2003 European heatwave, Nature Climate Change, 5(1), 46-50, doi:10.1038/nclimate2468.

Ciavarella, A., P. Stott, and J. Lowe (2017), Early benefits of mitigation in risk of regional climate extremes, Nature Climate Change, 5, 46-7, doi:10.1038/nclimate3259.

Cressey, D. (2016), Coral crisis: Great Barrier Reef bleaching is "the worst we've ever seen," Nature News, doi:10.1038/nature.2016.19747.

Frame, D., M. Joshi, E. Hawkins, L. J. Harrington, and M. de Roiste (2017), Populationbased emergence of unfamiliar climates, Nature Climate Change, 36, L06709-6, doi:10.1038/nclimate3297.

Henley, B. J., and A. D. King (2017), Trajectories toward the $1.5^{\circ} \mathrm{C}$ Paris target: Modulation by the Interdecadal Pacific Oscillation, Geophysical Research Letters, 5(6), 555-7, doi:10.1002/2017GL073480.

Hughes, T. P. et al. (2017a), Coral reefs in the Anthropocene, Nature, 546(7656), 82-90, doi:10.1038/nature22901.

Hughes, T. P. et al. (2017b), Global warming and recurrent mass bleaching of corals, Nature, 543(7645), 373-377, doi:10.1038/nature21707.

Jones, D. A., W. Wang, and R. Fawcett (2009), High-quality spatial climate data-sets for Australia, Australian Meteorological and Oceanographic Journal, 58(4), 233.

King, A. D., D. J. Karoly, and B. J. Henley (2017), Australian climate extremes at $1.5 \quad{ }^{\circ} \mathrm{C}$ and 2 Ratơf ElObiatatearatiagge, 6, 222-7, doi:10.1038/nclimate3296.

Lewis, S. C., A. D. King, and S. E. Perkins-Kirkpatrick (2016), Defining a new normal for extremes in a warming world, Bulletin of the American Meteorological Society, doi:10.1175/BAMS-D-16-0183.1. 
Lewis, S. C., and D. J. Karoly (2013), Anthropogenic contributions to Australia's record summer temperatures of 2013, Geophysical Research Letters, doi:10.1002/grl.50673.

Mitchell, D. et al. (2017), Half a degree additional warming, prognosis and projected impacts (HAPPI): background and experimental design, Geoscientific Model Development, 10(2), 571-583, doi:10.5194/gmd-10-571-2017.

Mitchell, D., C. Heaviside, S. Vardoulakis, C. Huntingford, G. Masato, B. P. Guillod, P. Frumhoff, A. Bowery, D. Wallom, and M. Allen (2016), Attributing human mortality during extreme heat waves to anthropogenic climate change, Environmental Research Letters, 11(7), 1-8, doi:10.1088/1748-9326/11/7/074006.

Morice, C. P., J. J. Kennedy, N. A. Rayner, and P. D. Jones (2012), Quantifying uncertainties in global and regional temperature change using an ensemble of observational estimates: The HadCRUT4 data set, Journal of Geophysical Research, 117(D8), D08101, doi:10.1029/2011JD017187.

National Academies of Sciences, Engineering, Medicine (2016), Attribution of Extreme Weather Events in the Context of Climate Change, National Academies Press.

Normille, D. (2016), Survey confirms worst-ever coral bleaching at Great Barrier Reef, Science, 1-10. Available from: http://www.sciencemag.org/news/2016/04/surveyconfirms-worst-ever-coral-bleaching-great-barrier-reef (Accessed 9 June 2016)

Pal, J. S., and E. A. B. Eltahir (2015), Future temperature in southwest Asia projected to exceed a threshold for human adaptability, Nature Climate Change, 107, 9552-4, doi:10.1038/nclimate2833.

Parker, T. J., G. J. Berry, and M. J. Reeder (2014), The Structure and Evolution of Heat Waves in Southeastern Australia, Journal of Climate, 27(15), 5768-5785, doi:10.1175/JCLI-D-13-00740.1.

Perkins, S. E. (2015), A review on the scientific understanding of heatwaves-their measurement, driving mechanisms, and changes at the global scale, Atmospheric Research, 164-165, 242-267, doi:10.1016/j.atmosres.2015.05.014.

Peters, G. P., R. M. Andrew, T. Boden, J. G. Canadell, P. Ciais, C. Le Quéré, G. Marland, M. R. Raupach, and C. Wilson (2012), The challenge to keep global warming below 2 ${ }^{\circ} \mathrm{C}$, Nature, 3(1), 4-6, doi:10.1038/nclimate1783.

Robine, J.-M., S. L. K. Cheung, S. Le Roy, H. Van Oyen, C. Griffiths, J.-P. Michel, and F. R. Herrmann (2008), Death toll exceeded 70,000 in Europe during the summer of 2003, Comptes Rendus Biologies, 331(2), 171-178, doi:10.1016/j.crvi.2007.12.001.

Stott, P. A., D. A. Stone, and M. R. Allen (2004), Human contribution to the European heatwave of 2003, Nature, 432(7017), 610-614, doi:10.1038/nature03089.

Taleb, N. N. (2007), The black swan: The impact of the highly improbable. 
Taylor, K. E., R. J. Stouffer, and G. A. Meehl (2012), An overview of CMIP5 and the experiment design, Bulletin of the American Meteorological Society, 93(4), 485, doi:10.1175/BAMS-D-11-00094.1.

Trewin, B. (2014), Special Climate Statement 48 - one of southeast Australia's most significant heatwaves, , 1-22.

UNFCCC (2016), Paris Agreement,, 1-27.

Victorian Department of Health (2009), January 2009 Heatwave in Victoria: an Assessment of Health Impacts, Victorian Government Department of Human Services, Melbourne, Victoria.

\section{Figures}

Figure 1. Comparison of observations and HAPPI. (a) Spatial extent of record-breaking DJF temperatures in 2012/2013, with the Coral Sea and NSW/VIC regions noted. (b) Observations for Australia-average DJF Tmean, (c), Coral Sea MAM Tmean (d) Victoria State-average daily Jan Tmax and (e) NSW State-average daily Jan Tmax. The 2006-2015 mean (red horizontal bars) and maximum observed anomaly occurring during 2006-2015 (red squares) are shown, though note that marginally higher daily Jan values occurred in 1939 , as marked. For each region, the simulated values in HAPPI are shown for HAPPI ${ }_{2006-}$ 2015 (black), $\mathrm{HAPPI}_{1.5}$ (blue) and $\mathrm{HAPPI}_{2}$ (red). The multi-model ensemble mean values for decadal mean, minimum and maximum are shown.
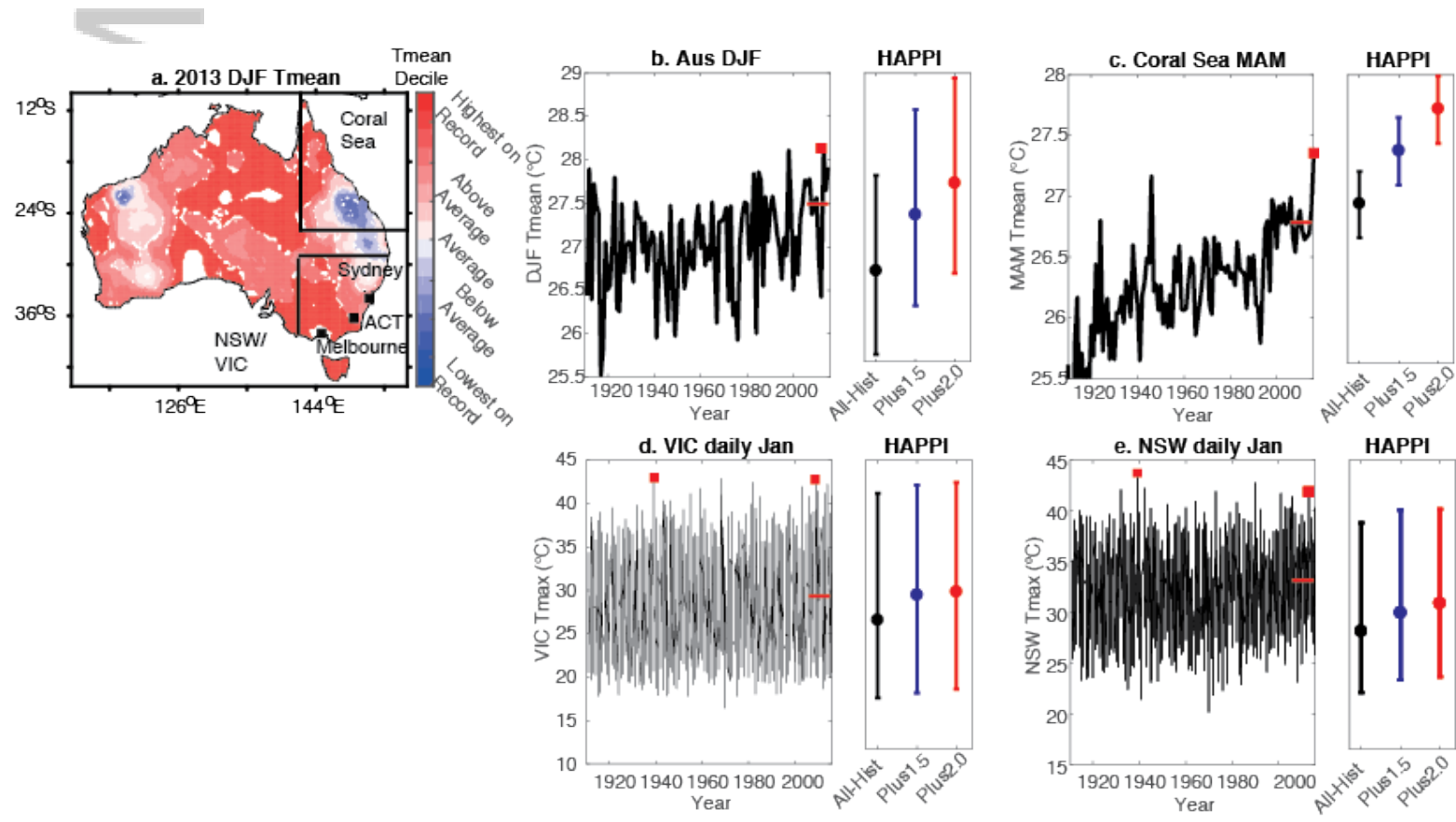

HAPPI

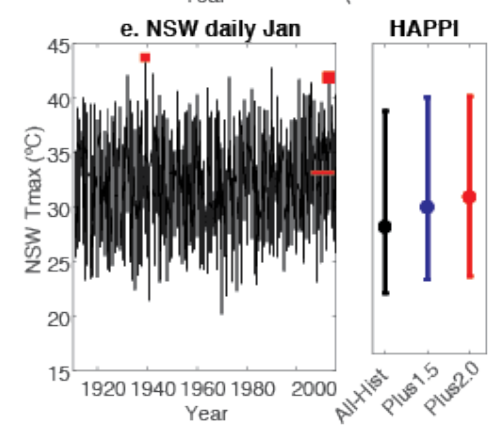

This article is protected by copyright. All rights reserved. 
Figure 2. Extreme events in HAPPI dataset. (a) Observed 2006-2015 mean Australia-wide

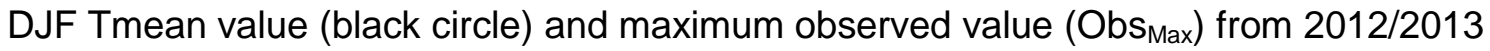
(black square and shown by horizontal dashed line). Comparison is shown with HAPPI $1.5^{\circ} \mathrm{C}$ (blue) and $2^{\circ} \mathrm{C}$ (red) simulations, which are indicated by the ensemble mean (circles) and $99^{\text {th }}$ percentile $\left(\mathrm{HAPPI}_{99}\right.$, shaded rectangle) values. Plots show the value of two simulated standard deviations above the HAPPI ensemble mean (for reference, dashed vertical colored lines) and the observationally constrained HAPPI range ( $\mathrm{HAPPI} \mathrm{obs}_{\text {, }}$ sold vertical colored lines). Where extremes up to $\mathrm{HAPPI}_{\text {obs }}$ values occur within the $\mathrm{HAPPI}_{99}$ range, events of these magnitudes are plausible under this level of global mean warming. Where events of greater magnitude than expected by the observational constraint are simulated in $\mathrm{HAPPI}_{99}$ events are described as black swans. Plots are also shown for Coral Sea MAM Tmean (b) and Victoria (c) and NSW (d) State-average daily Jan Tmax.

a. DJF Australia extremes

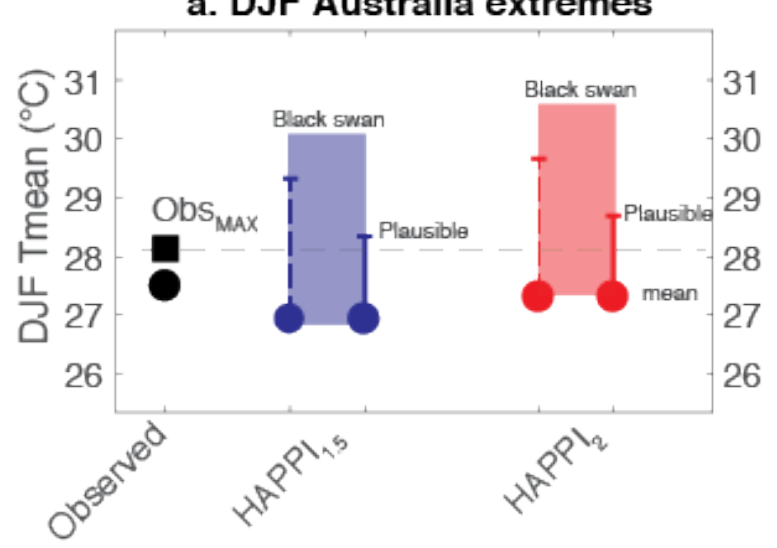

b. MAM Coral Sea extremes

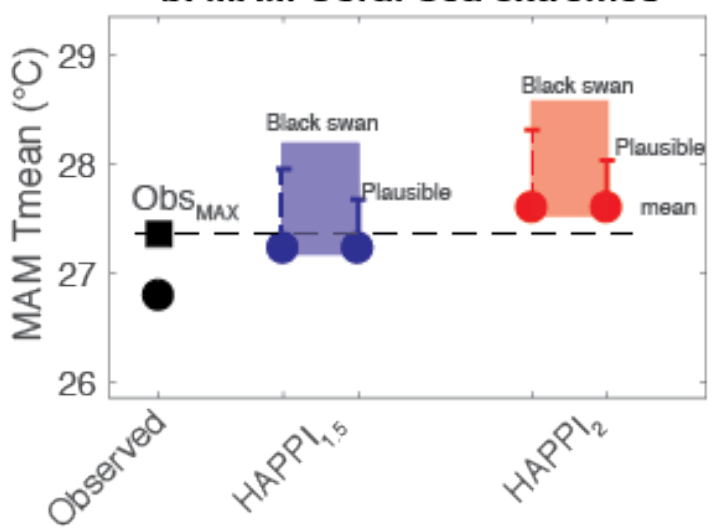

c. VIC Tmax Extremes

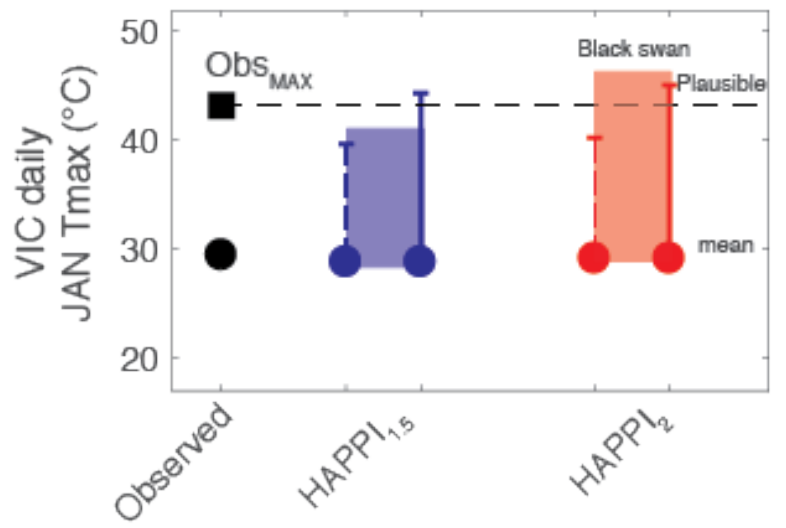

\section{d. NSW Tmax Extremes}

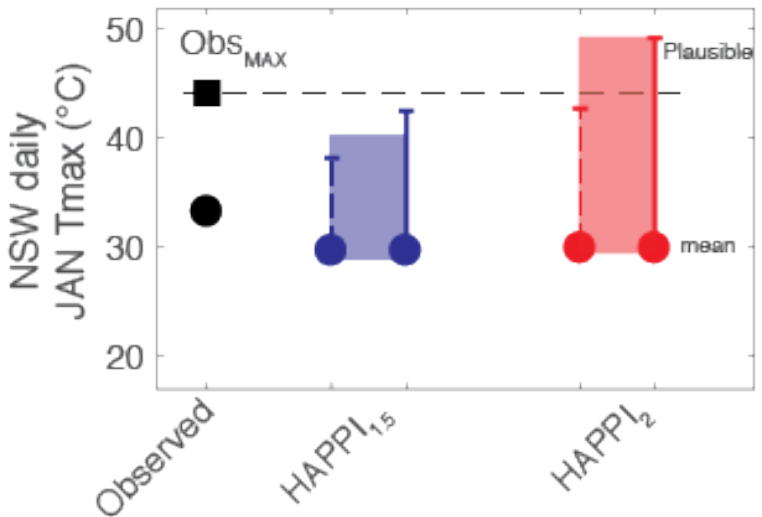
$\mathrm{HAPPl}_{1,800}$
$\mathrm{HAPPI}_{1,500} \mathrm{HAPPI}_{200}$
HAPPI
$\mathrm{HAPPI}_{200}$ 
Figure 3. End of 21st-Century temperatures in CMIP5. Multi-model ensemble mean Australian annual-average Tmean anomalies (a) for RCP2.6 and RCP8.5 ensemble mean values and $5^{\text {th }}-95^{\text {th }}$ percentile ranges (blue for RCP2.6 and red for RCP8.5) from 2006-2100. The vertical arrows represent the timing where the $1.5^{\circ} \mathrm{C}$ (dashed) and $2^{\circ} \mathrm{C}$ (solid) thresholds are breached for Australian annual Tmean in each experiment (blue for RCP2.6 and red for RCP8.5). Vertical bars indicate the end of century decadal-mean $95^{\text {th }}$ percentile values across the multi-model ensemble for RCP8.5 and RCP2.6 and the equivalent RCP8.5 2006-2015 values. Equivalent plots are shown for Australia DJF $\Delta$ Tmean (b), Coral Sea MAM $\Delta$ Tmean (c) and Victoria-state (d) and NSW (e) average daily January Tmax.

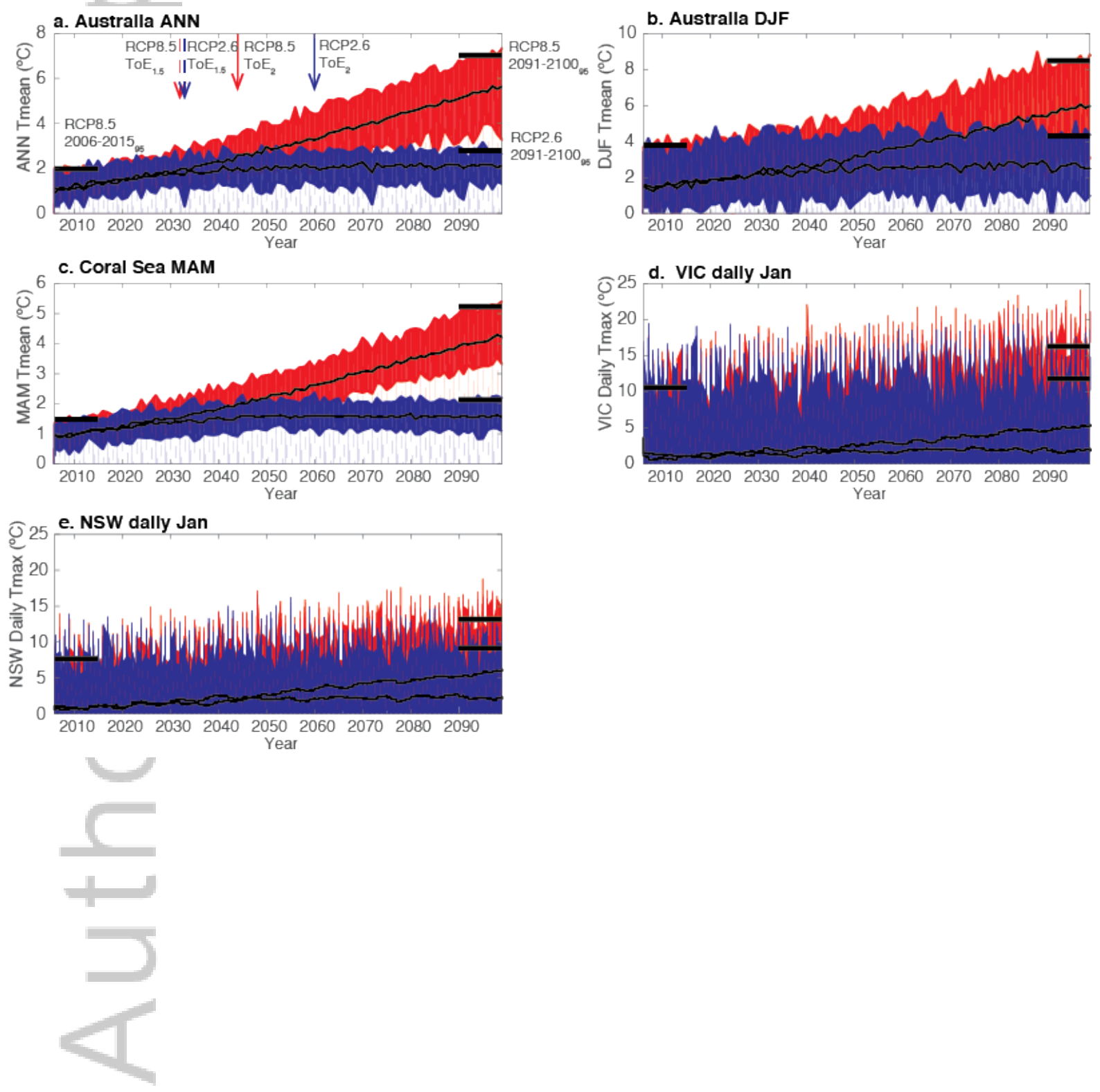

This article is protected by copyright. All rights reserved. 
Table 1. Observed and simulated extreme values. The observed maximum values for each metric $\left(\mathrm{Obs}_{\operatorname{Max}}\right)$ and the number of observed standard deviations $\left(\mathrm{N \sigma}_{\max }\right)$ above normal defining $\mathrm{Obs}_{\mathrm{Max}}$ for each metric. The value of the observationally constrained range (HAPPI ${ }_{\text {obs }}$ ) shown for each experiment, together with $99^{\text {th }}$ percentile simulated values $\left(\mathrm{HAPPI}_{99}\right)$. Where the observationally constrained range value is lower than HAPPI ${ }_{99}$ value, such extremes are plausible (light grey) if this warming threshold is breached, and the $\mathrm{HAPPI}_{99}$ value represents potential black swan events (dark grey) that do not scale with observed extremes.

\begin{tabular}{|c|c|c|c|c|c|c|}
\hline \multirow[b]{2}{*}{ Metric } & \multirow[b]{2}{*}{$\mathrm{Obs}_{\operatorname{Max}}\left({ }^{\circ} \mathrm{C}\right)$} & \multirow[b]{2}{*}{ NoObs_max } & \multicolumn{2}{|c|}{ HAPPI $1.5\left({ }^{\circ} \mathrm{C}\right)$} & \multicolumn{2}{|c|}{ HAPPI $2\left({ }^{\circ} \mathrm{C}\right)$} \\
\hline & & & HAPPI $_{1.5 / \text { Obs }}$ & $\mathrm{HAPPI}_{99}$ & $\mathrm{HAPPI}_{2 / \mathrm{Obs}}$ & $\mathrm{HAPPI}_{99}$ \\
\hline Australia DJF Tmean & 28.1 & 1.2 & 28.3 & 30.1 & 28.7 & 30.5 \\
\hline Coral Sea MAM Tmean & 27.4 & 1.3 & 27.7 & 28.2 & 28.0 & 28.6 \\
\hline VIC Daily Tmax & 43.1 & 2.9 & 44.3 & 40.3 & 44.9 & 46.8 \\
\hline NSW Daily Tmax & 44.1 & 3.0 & 42.4 & 40.5 & 47.2 & 47.9 \\
\hline
\end{tabular}

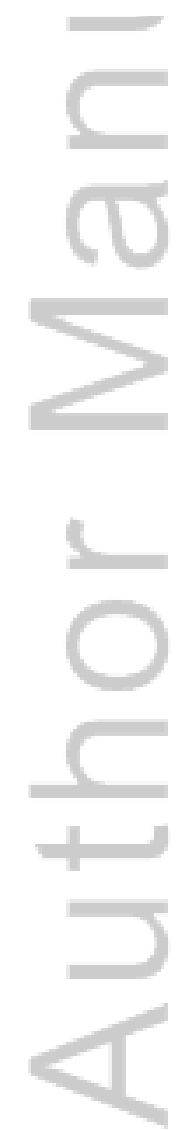

This article is protected by copyright. All rights reserved. 


\section{University Library}

\section{- M M N E R VA A gateway to Melbourne's research publications}

Minerva Access is the Institutional Repository of The University of Melbourne

Author/s:

Lewis, SC;King, AD;Mitchell, DM

Title:

Australia's Unprecedented Future Temperature Extremes Under Paris Limits to Warming

Date:

2017-10-16

Citation:

Lewis, S. C., King, A. D. \& Mitchell, D. M. (2017). Australia's Unprecedented Future Temperature Extremes Under Paris Limits to Warming. GEOPHYSICAL RESEARCH LETTERS, 44 (19), pp.9947-9956. https://doi.org/10.1002/2017GL074612.

Persistent Link:

http://hdl.handle.net/11343/293575 